\title{
Dendrometer and intra-annual tree growth: what kind of information can be inferred?
}

Annie Deslauriers, Sergio Rossi, Tommaso Anfodillo

Treeline Ecology Research Unit

Dipartimento Territorio e Sistemi Agro-Forestali

Università degli Studi di Padova

Viale dell'Università 16

35020 Legnaro (PD)

ITALY

E-mail of the author: annie.deslauriers@unipd.it

Tel: 390498272752

Fax: 390498272686 


\begin{abstract}
Dendrometer measurements provide time series composed of the rhythm of water storage fluctuations over the year and seasonal tree growth. For slow-growing trees however, difficulties have been found in the identification of crucial events such as growth onset, stem growth period and cessation, rendering it necessary to define what can be measured and at which time scale. The time scale mean the time interval (from one day to one month) at which stem radius variation is extracted. In this study, two conifer species were monitored by automatic band dendrometer to assess several time scales and analysis approaches. Data were collected from 8 trees of Picea abies (L.)
\end{abstract} Karst and Larix decidua L., growing at 1020 and $2080 \mathrm{~m}$ a.s.l. in the eastern Italian Alps, from 2000 to 2003. Time series of stem radius variation were extracted with different approaches, such as the stem cycle, daily mean and daily maximum. Several approaches can be used, as very similar time series of stem radius variations were produced with high coefficients of correlation among the series. At lower altitude, the approximate onset was identified at the beginning of May with a 10 days time scales, when the distribution of stem radius variation differed from zero. The main growth period, from May to June-July, corresponded mainly with earlywood cell formation. At higher altitude, a time scales of at least 15 days facilitated identification of the main period of stem growth only, corresponding with earlywood cell formation. Even if latewood cells were produced in August at both altitudes, the variability in stem radius changes was higher than the amount of growth in terms of cell-wood production. For slow-growing species of a cold environment, an understanding of the growth period, assessed with several time scales, is necessary when using time series of stem radius variation to perform growth and climate relationships. The period used for growth and climate analysis should correspond only with the main period of stem growth.

Keywords: automatic dendrometer, stem radius variation, time scale, radial growth 


\section{INTRODUCTION}

Continuous monitoring of stem radial variation throughout the year is crucial for understanding tree reaction to short-term changes in environmental conditions, such as temperature, soil water content and rainfall. This monitoring can be straightforward using automatic dendrometers. These instruments measure stem radial variation composed of diurnal rhythms of water storage depletion and replenishment (Kozlowski and Winget, 1964; Herzog et al., 1995; Offenthaler et al., 2001) and seasonal tree growth (Dünisch and Bauch, 1994; Downes et al., 1999; Tatarinov and Čermák, 1999; Tardif et al., 2001; Deslauriers et al., 2003b; Bouriaud et al., 2005). Because of the reversible stem shrinking and swelling, dendrometers have been criticized when used to measure short-term growth rates (Mäkinen et al., 2003; Zweifel and Häsler, 2001). These criticisms are, to some extend, founded as several authors reported difficulties in identifying crucial phenological events such as cambial growth onset and ending (Tardif et al., 2001; Deslauriers et al., 2003b), or in differentiating "growth" from "stem water content" variation in slow-growing species (Zweifel and Häsler, 2001). Therefore, in such a situation, variation in radial size measured by dendrometer is higher than the growth in terms of wood production, inevitably introducing an error in the estimated growth. Because of the usefulness of the instrument, several studies have been published in recent years describing stem growth phenology and/or performing growthclimate relationships (Dünisch and Bauch, 1994; Downes et al., 1999; Nicault et al., 2001; Tardif et al., 2001; Deslauriers et al., 2003b; Mäkinen et al., 2003; Yoda et al., 2003; Bouriaud et al., 2005). However, extraction of the growth signal often differed in the approach or time scale of analysis. In this study, the time scale mean at which time interval (from one day to one month) stem radius variation is extracted from the time 
series. It therefore remains to be defined what can be measured with the time series produced by dendrometer monitoring and at which time scale.

\section{Analysis approach}

In all approaches described in the literature to extract stem growth, the first step consisted of removing the daily fluctuations caused by stem shrinking and swelling. This is important as it determines how the daily stem variation will be calculated. Two categories of approach were defined according to how the stem variation is extracted. The daily approach consists of extracting one value per day from the time series (Tardif et al., 2001; Bouriaud et al., 2005). Tardif et al. (2001) averaged the $24 \mathrm{~h}$ reading circumference measurements obtained from 00:00 to 23:00 hours on a daily basis. Instead of averaging, Bouriaud et al. (2005) extracted the daily maximum. With the daily approach, the time series can be quickly reduced from 24 raw data per day (or more) to just one. Other transformations are then used (e.g. differences between two or more successive values) to calculate the stem variation.

The stem cycle approach is based on the patterns of stem shrinking and swelling (Herzog et al., 1995; Downes et al., 1999). Three distinct phases of contraction, expansion and stem radius increase are isolated and separately analysed and often last approximately 24 hours. This approach in 3 phases is a reduction of the 5 phases of the diurnal courses of the flow through the stem and the related change in stem radius defined by Herzog et al. (1995). With this division, the amplitude of radial variations (contraction, stem expansion, in $\mu \mathrm{m}$ or $\mathrm{mm}$ ) as well as their duration (in hours) can be calculated. The stem cycle approach was used for growth and climate analyses (Downes et al., 1999; Deslauriers et al., 2003b) as well as for comparing growth and wood 
properties (Wimmer et al., 2002). Although needing appropriate algorithms for the phase and cycle divisions and growth extraction, this approach follows the periodic sap flow variations.

\section{Time scale}

Daily stem variation produced by the different analysis approaches and its cumulative sums over the year are the most common representation (Carrer et al., 1998; Downes et al., 1999; Tatarinov and Čermák, 1999; Nicault et al., 2001; Tardif et al., 2001; Deslauriers et al., 2003b; Yoda et al., 2003). However, in order to obtain a different representation of the rates of change in stem radius during a certain period of time, different time scales were used. According to Nicault et al. (2001), analysis of growth rates calculated over a period of 15 days enhances different periods of growth activity or rest compared with the daily rates. Differences over 5 days were also used by Bouriaud et al. (2005) to calculate growth rates from daily maximum values. A larger scale, from 5 to 30 days representations of the rates of stem changes, could improve identification of the phases of stem activity by eliminating the oscillating patterns in the daily time series. The time scale used should depend on both the climatic condition of a specific site (e.g. dryness of the site, temperature) and/or the growth rate of the species.

\section{Objectives of the study}

There are several approaches and scales of analysis, but no information is available on the more suitable methods for performing extraction of radial stem variation for slowgrowing trees, where radial stem growth is generally more difficult to identify. In this study, stem radius variation was measured from 2000 to 2003 at two altitudes in the south-eastern Italian Alps to (1) describe the category of stem cycles and determine 
their frequency during the year, (2) assess the smallest temporal scale at which a given event (growth onset, intensive period of growth, growth cessation) can be identified and (3) compare the different analysis approaches (stem cycle, daily maximum and daily mean). 


\section{Materials and methods}

\section{Study area}

Data were collected from 2 conifer species, Picea abies (L.) Karst and Larix decidua L., at different altitudes in the eastern Italian Alps (Cortina d'Ampezzo, Dolomites). The high altitude site, Cinque Torri 1 (5T1), was located at the timberline ecotone at $2080 \mathrm{~m}$ a.s.l. $\left(46^{\circ} 27^{\prime} \mathrm{N}, 12^{\circ} 08^{\prime} \mathrm{E}\right)$. The timberline was a mixed stand formed by dispersed Larix decidua L., Pinus cembra L. and Picea abies (L.) Karst. that had colonized an area of abandoned pasture lands. The trees establishment period ranged from 1943 to 1971. San Vito (SVT) was located at the bottom of the valley at $1020 \mathrm{~m}$ a.s.1. $\left(46^{\circ} 26^{\prime} \mathrm{N}, 12^{\circ} 13^{\prime} \mathrm{E}\right)$ and was composed of 70 years-old trees of P. abies and Pinus sylvestris L. mixed with 20 years-old trees of L. decidua. At both sites, the study covered four growing seasons, from 2000 to 2003 with two trees per species per sites analysed

\section{Data collection}

Automatic band dendrometers (Tecno Penta, Teolo (PD), Italy) were used to continuously monitor tree growth. These instruments measure linear displacement of a band wrapped around the trunk. Thin strips of Teflon foil were placed to reduce friction between the bark and the band. The operating principle of the dendrometer is based on the use of a linear potentiometer. As the stem expands and contracts, the band transmits a signal to the potentiometer. Displacement of the potentiometer is resolved to $6 \mu \mathrm{m}$ over an unadjusted range of $20^{\prime} 000 \mu \mathrm{m}$. The band had a thermal coefficient of linear expansion of $11 \mu \mathrm{m} . \mathrm{m}-1 .{ }^{\circ} \mathrm{C}-1$, representing an error of about $1 \%$ on the extracted values. Dendrometers were installed on two trees for each species at a height of about $1.3 \mathrm{~m}$. Raw data were taken every 15 minutes and stored in a datalogger (CR10X, Campbell Scientific Corporation). From the raw data, hourly means were calculated and 
all the circumference measurements were divided by $2 \pi$, thus providing linear measurements of the radius.

\section{Extraction of stem radius variation}

For the stem cycle approach, extraction of stem radius variation $(\Delta \mathrm{R})$ was performed by dividing the stem cycle into three distinct phases (Fig. 1a) covering approximately 24 hours (Downes et al., 1999, Deslauriers et al., 2003b): the contraction phase (1), period between the morning maximum and daily minimum; expansion phase (2), total period from the daily minimum to the following morning maximum; stem radius increment phase (3), part of the expansion phase from the time when the stem radius exceeds the morning maximum until the next maximum. The difference between the maximum of expansion and the beginning of the third phase represented the $\Delta \mathrm{R}+$ estimate $(\mathrm{mm})$. When the previous cycle maximum was not reached, stem radius decrease $(\Delta \mathrm{R}-, \mathrm{mm})$ was calculated but no third phase was defined (Fig. 1a). The result of this extraction was a continuous time series composed of the net oscillation ( $\Delta \mathrm{R}$ amplitude, $\mathrm{mm}$ ) of the stem radius (Fig. 1a, black line). Phase division and calculation of the stem radius variation were performed with a special routine written in $\mathrm{SAS}^{\circledR}$. The stem circadian cycle usually lasted approximately 24 hours, but heavy rain in summer or freeze-thaw events in the rest of the year caused long cycles of more than 24 hours (Zweifel and Häsler, 2000), due to a longer contraction or expansion phase (Fig. 1, LG cycle). Cycles lasting around 24 hours ( \pm 3 hours) were defined as regular (REG), those lasting more than 28 hours were defined as long cycles (LG). The very short cycles, lasting less than 20 hours were not very frequent compared with the long cycles and were considered as regular. The monthly frequency distributions $(\%)$ of the REG $-\mathrm{LG}$ or the $\Delta \mathrm{R}+-\Delta \mathrm{R}-$ cycles were calculated for trees and years. Differences in the monthly frequency 
distribution of the REG-LG or $\Delta \mathrm{R}+-\Delta \mathrm{R}$ - cycles were Chi-Square tested $\left(\chi^{2}\right)$ for each species. As the monthly frequency distribution was similar between the years, the analyses were performed on all years together.

For the daily approach, two series of stem radius variation were extracted on a daily basis for each tree and year (Tardif et al., 2001; Bouriaud et al., 2005). The daily mean and daily maximum were calculated from the raw data, i.e. from the 24 hours values measured from 00:00 to 23:00 hours. The daily stem radius variation was then calculated for both series by calculating the difference between the mean/max value of two consecutive days. A continuous daily time series composed of the net oscillation (amplitude, $\mathrm{mm}$ ) of the stem radius variation was then calculated (Fig. 1b, black lines). The other transformations used by Tardif et al. (2001) and Bouriaud et al. (2005) as first-order differencing or trend removing, were not reproduced as the objective was to compare unrefined series.

\section{Scaling of stem variation}

From the time series of stem radius variation obtained ( $\Delta \mathrm{R}+-\Delta \mathrm{R}-$ Fig. 1, black line), groupings were made to examine the distribution of stem radius variation values at different scales. To determine the smallest scales at which a given event (i.e. growth onset, period of growth, growth cessation) can be identified, value distributions of stem radius variation were examined at 5, 7, 15, 20, 25 and 30-day intervals (30 days corresponding to a monthly scale). A student's t-test for mean location was used to assess if the mean of a specific distribution was equal to zero $(\mu=0)$. In this study, we assumed that radial growth occurred when the distributions of the values were positive and significantly different from zero. As most distributions were asymmetric, thus 
violating the normality assumptions of the one-sample t-test, data were transformed by the square root $\left(y^{\prime}=\sqrt{y+1.5}\right)$. The value of 1.5 was added to obtain only positive data and to counterbalance very small data (Zar, 1999). After transformation, all data were re-centered to zero. 


\section{RESULTS}

\section{Comparison between approaches}

Extraction of stem radius variations was performed using stem cycle, daily mean and daily maximum approach (Fig. 1). Very similar series were obtained with the 3 approaches throughout the year, with high and significant correlation coefficients (Table 1 and Fig. 2). However, differences were found in the amplitude of the stem variation. Higher amplitude was calculated with the stem cycle approach and lower with the daily maximum approach. When LG cycles occurred, the stem expansion calculated with the stem cycle approach lasted several days (Fig. 1). Therefore, extracting one value per day (mean or max) sliced one continuous $\Delta \mathrm{R}+$ in several parts (days), thus extracting lower values (Fig. 2). The same also occurred when contraction lasted several days, especially in winter (Fig. 2). For both sites and species, correlations between the daily mean and daily maximum series were the highest as both approaches were very similar (Table 1). Correlations between the daily mean and stem cycle series were generally higher than those calculated for the daily maximum and stem cycle series.

\section{Changes in $\Delta R$ amplitude during the year}

The pattern of $\Delta \mathrm{R}$ amplitude extracted with the stem cycle approach changed during the year (Fig. 3). At both sites, from December to March, $\Delta \mathrm{R}$ variations were characterized by very high amplitudes, with values of up to $0.6 \mathrm{~mm}$ in $P$. abies. At 5T1, high stem variation persisted in April. For L. decidua, much lower variations were recorded during winter, with values ranging between -0.4 and $0.4 \mathrm{~mm}$. In SVT, the months of March and April were characterized by smaller variations in $\Delta \mathrm{R}$ (between -0.05 and $0.05 \mathrm{~mm}$ ), producing plateaus before the start of radial growth with cumulative sums (Fig. 3, thick black lines). In 5T1, cumulative sums revealed plateaus before the start of radial growth 
only in 2001 and 2002 for P. abies (Fig. 3). However, the end of the plateau did not correspond exactly with start of cell division and expansion observed by using the microsample technique (Fig. 3). In 2001, for example, cells in radial expansion were observed on May 25 but, by observing the cumulative sums, the intensive stem increase began on June 1, about one week later (Rossi 2003). The stem growing period, which was mainly from June to mid-August in 5T1 and from May to mid-August in SVT, was characterized by a sharp increase in the cumulative sums. During this period, very small $\Delta \mathrm{R}$ - values were calculated and $\Delta \mathrm{R}+$ varied between 0 and $0.2 \mathrm{~mm}$. From mid-August to the end of October in 5T1, and the end of November in SVT, the cumulative sums were characterized by plateaus created by several groups of $\Delta R+$ and $\Delta R-$ (Fig. 3). The amplitudes of $\Delta \mathrm{R}$ variations in this period were often similar to the ones observed during the growing period but with higher $\Delta \mathrm{R}-$.

To understand cycle distribution, the monthly frequency of REG - LG (Fig. 4) and $\Delta \mathrm{R}+$ $-\Delta \mathrm{R}$ - cycles (Fig. 5) were analysed. All years were considered together in the $\chi^{2}$ analysis as the monthly distribution was always similar. In both sites, significant differences were found in the frequency distribution of REG-LG cycles (Fig. 4). In 5T1, $30 \%$ to $50 \%$ of LG cycles were observed during the year, except in May-August when their frequencies were $20-25 \%$, revealing significant differences in the monthly distribution for P. abies $\left(\chi^{2}=62.5, \mathrm{P}<0.001\right)$. For $L$. decidua, significant differences were found among months $\left(\chi^{2}=20.8, P=0.035\right)$ with $70-80 \%$ of REG cycles, except for November with $52 \%$ of REG cycles. In SVT, bell shaped distributions were found with higher frequency of LG cycles during winter (35-45\%) and a lower frequency during summer (5-20\%) (Fig. 4). Significant differences in frequency distribution were found for both $P$. abies $\left(\chi^{2}=93.5, \mathrm{P}<0.001\right)$ and L. decidua $\left(\chi^{2}=42.8, \mathrm{P}<0.01\right)$. 
During the year, the occurrence of $\Delta \mathrm{R}+$ and $\Delta \mathrm{R}$ - cycles (Fig. 5) changed significantly for all species and sites $\left(\chi^{2}, \mathrm{P}<0.001\right)$. From May to July, $\Delta \mathrm{R}+$ cycles were more frequent than $\Delta \mathrm{R}$ - in both species. The lowest frequencies of $\Delta \mathrm{R}$ - cycles were observed in June in 5T1 (20\%) and May-June in SVT (10-20\%). From August to October, the frequency of $\Delta \mathrm{R}$ - cycles increased because of the end of radial growth, with the highest frequency being observed in September. More $\Delta \mathrm{R}$ - cycles were observed (55-60\%) during winter (December to February), while more $\Delta \mathrm{R}+$ cycles were observed (60-70\%) during spring re-hydration (from March to April-May).

\section{Scaling of stem radius variations}

To determine the smallest scales at which stem growth can be identified, value distributions of stem radius variation (stem cycle approach) were examined at several scales (Figs. 6-9). In this study, stem growth was considered as taking place when the value distributions were positive and significantly different from zero, and compared with the period of cell production when these data were available.

In 5T1, high variation persisted when value distributions were represented at scales of less than 10 days (Figs. 6-7). At 7-day intervals, few weeks of stem growth were identified, especially for $P$. abies, mostly initiating at the beginning or in the second half of June (Fig. 6). Therefore, for both species, onset of stem radial growth could not be identified by using smaller scales ( 5 or 7 days), nor the period of stem growth. At $15-$ day intervals, wide variations were found among species and years, with 15-75 days of stem growth occurring mainly from June to mid-July. In May 2001, 2002 and 2003, the 15-day distributions were not significantly different from zero, indicating no high re- 
hydration or growth event for $P$. abies that facilitated identification of the intensive growth period. After mid-July, the distributions had a mean not different from zero or negative. Similar results were found with the monthly distributions. For L. decidua, periods of growth were identified in June and July. In 2000-2001 however, the distributions of April and May had positive means and significantly different from zero, introducing confusion in the identification of radial growth onset and main period of growth (Fig. 7). In all measured years, the month of August had a distribution not significantly different from zero $(p>0.05)$.

At a scale of 7 days in SVT, stem growth lasted from 4 to 8 weeks in May-July for both species (Figs. 8-9). For P. abies, the onset of radial stem growth was identified with precision at scales higher than 10 days in 2003 (Fig. 8). In both species, most of the distributions at scale $>10$ days were not significantly different from zero in April, indicating no re-hydration or growth process and thus facilitating identification of the onset and period of radial growth. As with the 5T1 site, the month of August had means near zero or negative. 


\section{DISCUSSION}

\section{Approach of analysis}

The extraction of stem radius variation throughout the year is the most direct method to obtain a continuous time series that can be used for intra-annual growth study. Several approaches can be used as similar results of stem radius variation were found. The stem cycle approach had the advantage of extracting continuous stem contraction or expansion and is suggested when high frequency of LG cycles occur. However, the series needed appropriate algorithms to separate the cycles compared with the other approaches. Alternatively, the daily mean approach provided results more similar to the stem cycle than the daily maximum. As the daily mean approach also takes the amount of contraction into account, correlations between stem cycle and daily mean were generally higher for both species and site. Bouriaud et al. (2005) selected the daily max instead of daily means as the highest stem water potential values occurred at daily radius maximum values. However, both methods produced almost equal series of stem variation with coefficients of correlation ranging from 0.7 to 0.89 .

\section{Stem variation and time scale}

From tropical to temperate and colder climates, determining the period of stem growth by dendrometer measurement is an important issue when studying growth and climate relationships (Downes et al., 1999; Worbes, 1999; Deslauriers et al., 2003b; Biondi et al., 2005). However, it has been found to be much more complex in colder environments where tree growth is slow (Mäkinen et al., 2003). The daily fluctuations, mostly restricted to extensible tissues outside the cambium (Kozlowski et al., 1991; Zweifel et al., 2000), can account for a fraction of the stem variation due to growth because of increased-decreased water storage. When trees are growing slowly and for a 
short period of time, this fraction will be higher than growth, introducing biases in the analysis. Although the thickness of the elastic part of the bark can also account for a fraction of the contraction-expansion measured, the radial variations were not only proportional to bark thickness because $L$. decidua, the species with the thicker bark, did not showed higher radial variations.

The distribution of $\Delta \mathrm{R}+$ and $\Delta \mathrm{R}$ - amplitude and frequency during a whole year must be understood as a function of the physiological state of the trees, which changed over the seasons. Very high stem variations were extracted during winter, especially at higher altitude, caused by alternating frost shrinkage and thaw expansion due to temperature changes (Zweifel and Häsler, 2000). These high variations will take place as LG cycles, at frequencies of $30-50 \%$ in winter.

Spring re-hydration followed winter. Identification of this period in the signal recorded by the dendrometers is crucial when trying to assess radial growth in a cold environment, because the re-hydration phase might easily be confused with the onset of radial growth (Kozlowski and Winget, 1964). When present, re-hydration occurred in March at lower altitude, followed by plateaus that made identification of the approximate onset of radial growth easier. In a more temperate environment, the presence of plateaus in cumulative sums, before the growing period, also facilitated identification of the approximate onset of stem radial growth in Pinus halepensis Mill. (Nicault et al., 2001) and P. abies (Bouriaud et al., 2005). At lower altitude, the approximate onset was identified at the beginning of May with about ten days of precision in 2003, when the distribution of stem radius variation was different from zero (at scale >10 days). At higher altitude, there were difficulties in identifying the onset 
when tree stem re-hydrations were still occurring in late spring, especially in $P$. abies. In these cases, the accuracy of all representations, from $\Delta \mathrm{R}$ variations to cumulative sums and 5-30 days distributions, were inappropriate as high variations were found. Therefore, other techniques, such as micro-sampling (Deslauriers et al., 2003a) or pinning (Schmitt et al., 2004) have to be used to identify the onset of radial growth.

At lower altitude, the main period of stem radial growth, occurring from May to July, was easily identified with the continuous sums or with the distribution of the value at scales higher than 10 days. The main period identified in 2003 (May-June) at scale >10 days, corresponded only with earlywood formation, as latewood transition occurred at the end of June in 2003 at SVT (Tedoldi, 2004). At higher altitude, the main periods of stem growth were identified mainly at scale $>15$ days and corresponded to June and July when mainly earlywood cells are being formed as the earlywood to latewood transition occurred around mid-July at 5T1 (Rossi, 2003; Rossi et al., 2006). In August, when latewood cells are completing enlargement phase, the amount of growth in terms of cell-wood production is small and much lower than the variability in stem radius changes, thus introducing an error in the growth estimated. In 2003, for example, all distributions of stem radius variation in August were equal to zero or different but with negative means, although cells were produced until August 22 in $P$. abies in SVT (Tedoldi, 2004) and August 10 in both species in 5T1 (Rossi et al., 2006). 


\section{CONCLUSION}

Stem variation extraction from raw dendrometer data can be done using several approaches with very minor differences. Stem radius variations or cumulative sums, although being the most common (Carrer et al., 1998; Downes et al., 1999; Tatarinov and Čermák, 1999; Nicault et al., 2001; Tardif et al., 2001; Deslauriers et al., 2003b; Yoda et al., 2003), were not sufficient for the identification of crucial periods at our particular site. Distributions of the values at scales $>10$ days facilitated identification of the growth onset and main period of stem growth at lower altitude. At higher altitude, scales >15 days facilitated identification of the main period of stem growth only, corresponding with earlywood cell formation. Only the main period of growth should therefore be included when performing relationships with other parameters, excluding the few weeks at the beginning or end of stem radial increase, when measurement variability is higher than radial growth. At higher altitude (as in 5T1), only June and July should be included in growth and climate analysis and at lower altitude (as in SVT), only May, June and July. 


\section{ACKNOWLEDGEMENT}

This work was funded by MIUR-PRIN 2000 (MM07384744_003), MIUR-PRIN 2002 (2002075152) and MAXY 2004 (CPDA045152). The authors wish to thank C. Filoso,

F. Fontanella, R. Menardi and V. Carraro for technical support. 


\section{REFERENCES}

Biondi, F., Hartsough, P.C., Galindo Estrada, I., 2005. Daily weather and tree growth at the tropical treeline of North America. Arctic, Antarctic and Alpine Research 37, $16-24$

Bouriaud, O., Leban, J.-M., Bert, D., Deleuze, C., 2005. Intra-annual variations in climate influence growth and wood density of Norway spruce. Tree Physiology 25, 651-660.

Carrer, M., Anfodillo, T., Urbinati, C., Carraro, V., 1998. High -altitude forest sensitivity to global warming: results from long-term and short-term analyses in the Eastern Italian Alps, in: Beniston, M., Innes, J.L. (Eds.), The impacts of climate variability on forest, Lecture notes in earth sciences, 74. Springer, Berlin, pp. 171-189.

Deslauriers, A., Morin, H., Bégin, Y., 2003a. Cellular phenology of annual ring formation of Abies balsamea in the Québec boreal forest (Canada). Canadian Journal of Forest Research 33, 190-200.

Deslauriers, A., Morin, H., Urbinati, C., Carrer, M., 2003b. Daily weather response of balsam fir (Abies balsamea (L.) Mill.) stem radius increment from dendrometer analysis in the boreal forests of Québec (Canada). Trees 17, 477-484.

Downes, G., Beadle, C., Worledge, D., 1999. Daily stem growth patterns in irrigated Eucalyptus globulus and E. nitens in relation to climate. Trees 14, 102-111.

Dünisch, O., Bauch, J., 1994. Influence of soil substrate and drought on wood formation of spruce (Picea abies [L.] Karst.) under controlled conditions. Holzforschung $48,447-457$.

Herzog, K.M., Häsler, R., Thum, R., 1995. Diurnal changes in the radius of a subalpine Norway spruce stem: their relation to the sap flow and their use to estimate 
transpiration. Trees 10, 94-101.

Kozlowski, T.T., Kramer, P.J., Pallardy, S.G., 1991. The physiological ecology of woody plants. Academic Press, San Diego.

Kozlowski, T.T., Winget, C.H., 1964. Diurnal and seasonal variation in radii of tree stems. Ecology 45, 149-155.

Mäkinen, H., Nöjd, P., Saranpää, P., 2003. Seasonal changes in stem radius and production of new tracheids in Norway spruce. Tree Physiology 23, 959-968.

Nicault, A., Rathgeber, C., Tessier, L., Thomas, A., 2001. Observations sur la mise en place du cerne chez le pin d'Alep (Pinus halepensis Mill.): confrontation entre les mesures de croissance radiale, de densité et les facteurs climatiques. Annales des Sciences Forestières 58, 769-784.

Offenthaler, I., Hietz, P., Richter, H., 2001. Wood diameter indicates diurnal and longterm patterns of xylem water potential in Norway spruce. Trees 15, 215-221.

Rossi, S., 2003. Intra-annual dynamics of tree-ring formation and effects of the environmental factors at the timberline in the Eastern Alps. PhD dissertation, University of Padova, Italy.

Rossi, S., Deslauriers, A., Anfodillo, T., 2006. Assessment of cambial activity and xylogenesis by microsampling tree species: an example at the Alpine timberline. IAWA Journal 27, 383-394.

Schmitt, U., Jalkanen, R., Eckstein, D., 2004. Cambium dynamics of Pinus sylvestris and Betula spp. in the northern boreal forest in Finland. Silva Fennica 38, $167-$ 178.

Tardif, J., Flannigan, M., Bergeron, Y., 2001. An analysis of the daily radial activity of 7 boreal tree species, Northwestern Québec. Environmental Monitoring and Assessment 67, 141-160. 
Tatarinov, F., Čermák, J., 1999. Daily and seasonal variation of stem radius in oak. Annals of Forest Science 56, 579-590.

Tedoldi, L., 2004. Analisi intra-annuale della formazione dell'anello lungo il fusto di un individuo di Picea abies (L.) Karst. Master dissertation, University of Padova, Italy.

Wimmer, R., Downes, G.M., Evans, R., 2002. High-resolution analysis of radial growth and wood density in Eucalyptus nitens, grown under different irrigation regimes. Annals of Forest Science 59, 519-524.

Worbes, M., 1999. Annual growth rings, rainfall-dependent growth and long-term patterns of tropical trees from the Caparo Forest Reserve in Venezuela. Journal of Ecology 87, 391-403.

Yoda, K., Wagatsuma, H., Suzuki, M., Suzuki, H., 2003. Stem diameter changes before bud opening in Zelkova serrata samplings . Journal of Plant Research 116, 1318.

Zar, J.H., 1999. Biostatistical analysis. Upper Saddle River, New Jersey.

Zweifel, R., Häsler, R., 2000. Frost-induced reversible shrinkage of bark of mature subalpine conifers. Agriculture and Forest Meteorology 102, 213-222.

Zweifel, R., Häsler, R., 2001. Dynamics of water storage in mature subalpine Picea abies: temporal and spatial patterns of change in stem radius. Tree physiology $21,561-569$.

Zweifel, R., Item, H., Häsler, R., 2000. Stem radius changes and their relation to stored water in stems of young Norway spruce trees. Trees 15, 50-57. 


\section{Caption list}

Table 1. Pearson correlation coefficients (r) among the annual series of stem radius variation extracted with the stem cycle, daily mean and daily maximum approaches for P. abies and L. decidua in SVT and 5T1 from 2000 to 2003. All the correlation coefficients were significant at $p<0.001$.

Figure 1. Stem cycle approach a: The stem cycle divided into three distinct phases for P. abies in 2003 at $\mathrm{SVT}$. The stem radius increment $(\Delta \mathrm{R}+)$ amplitude (black line) was calculated when the stem radius exceeds the morning maximum until the subsequent maximum. A $\Delta \mathrm{R}$ - was calculated when the previous cycle maximum was not reached (black line). A regular cycle (REG) lasts about 24 hours while long cycle (LG) lasts more than one day and is normally characterised by an expansion phase (2) of more than one day. Daily approach $\mathbf{b}$ : Time series of daily radius variation extracted, for both series, by calculating the difference between the mean/max values of two consecutive days.

Figure 2. Comparison between the time series of stem radius variation ( $\mathrm{mm}$ ) extracted with the stem cycle, daily mean and daily max approaches for L. decidua in SVT, 2003.

Figure 3. Time series of $\Delta \mathrm{R}$ (thin line) and cumulative sums $\Delta \mathrm{R}$ (thick line) for $P$. abies and L. decidua from 2000 to 2003 in SVT (black) and 5T1 (grey). The arrows in 2001, 2002 and 2003 represent the beginning and end of stem radial growth found with the micro-sampling technique at those site (Rossi, 2003; Rossi et al., 2006; Tedoldi, 2004). 
Figure 4. Frequency distribution (\%) of the regular (REG) and long (LG) cycles during the different months of the year for P. abies and L. decidua in 5T1 and SVT.

Figure 5. Frequency distribution $(\%)$ of $\Delta \mathrm{R}$ - and $\Delta \mathrm{R}+$ during the different months of the year for P. abies and L. decidua in 5T1 and SVT.

Figure 6. Stem radius variation distribution $(\mu \mathrm{m})$ of $P$. abies in $5 \mathrm{~T} 1$ grouped at 7,15 and 30 days from 2000 to 2003. Distributions highlighted in grey were significantly different from zero (One-sample t-test $p<0.05$, square root transformation). The boxplots are expressed as $25-75 \%$ on the distribution with the central bar representing the mean. The dates of earlywood (EW) and latewood (LW) cell division (arrows) were obtained with the micro-sampling technique (Rossi, 2003; Rossi et al., 2006).

Figure 7. Stem radius variation distribution $(\mu \mathrm{m})$ of $L$. decidua in $5 \mathrm{~T} 1$ grouped at 7,15 and 30 days from 2000 to 2003. Distributions highlighted in grey were significantly different from zero (One-sample t-test $p<0.05$, square root transformation). The boxplots are expressed as $25-75 \%$ on the distribution with the central bar representing the mean. The dates of earlywood (EW) and latewood (LW) cell division (arrows) were obtained with the micro-sampling technique (Rossi, 2003; Rossi et al., 2006).

Figure 8. Stem radius variation distribution $(\mu \mathrm{m})$ of $P$. abies in SVT grouped at 7, 15 and 30 days from 2000 to 2003. Distributions highlighted in grey were significantly different from zero (One-sample t-test $p<0.05$, square root transformation). The boxplots are expressed as $25-75 \%$ on the distribution with the central bar representing the 
mean. The dates of earlywood (EW) and latewood (LW) cell division (arrows) were obtained with the micro-sampling technique (Tedoldi, 2004).

Figure 9. Stem radius variation distribution $(\mu \mathrm{m})$ of $L$. decidua in SVT grouped at 7, 15 and 30 days from 2000 to 2003. Distributions highlighted in grey were significantly different from zero (One-sample t-test $p<0.05$, square root transformation). The boxplots are expressed as $25-75 \%$ on the distribution with the central bar representing the mean. 
Table 1

\begin{tabular}{cccccc}
\hline \hline & \multicolumn{2}{c}{ Y.abies } & \multicolumn{2}{c}{ L.decidua } \\
& & SVT & $\mathbf{5 T 1}$ & SVT & $\mathbf{5 T 1}$ \\
\hline \hline \multirow{2}{*}{ Daily mean } & $\mathbf{2 0 0 0}$ & 0.78 & 0.84 & 0.78 & 0.86 \\
vs & $\mathbf{2 0 0 1}$ & 0.73 & 0.79 & 0.84 & 0.85 \\
Daily max & $\mathbf{2 0 0 2}$ & 0.82 & 0.85 & 0.89 & 0.86 \\
& $\mathbf{2 0 0 3}$ & 0.72 & 0.80 & 0.70 & 0.81 \\
\hline \multirow{2}{*}{ Daily mean } & $\mathbf{2 0 0 0}$ & 0.78 & 0.71 & 0.84 & 0.79 \\
vs & $\mathbf{2 0 0 1}$ & 0.68 & 0.74 & 0.76 & 0.73 \\
Stem cycle & $\mathbf{2 0 0 2}$ & 0.75 & 0.69 & 0.77 & 0.61 \\
& $\mathbf{2 0 0 3}$ & 0.71 & 0.62 & 0.73 & 0.67 \\
\hline \multirow{2}{*}{ Daily max } & $\mathbf{2 0 0 0}$ & 0.67 & 0.56 & 0.75 & 0.74 \\
vs & $\mathbf{2 0 0 1}$ & 0.78 & 0.68 & 0.77 & 0.63 \\
Stem cycle & $\mathbf{2 0 0 2}$ & 0.72 & 0.72 & 0.62 & 0.61 \\
& $\mathbf{2 0 0 3}$ & 0.69 & 0.60 & 0.75 & 0.64 \\
\hline \hline
\end{tabular}




\section{Figure 1}
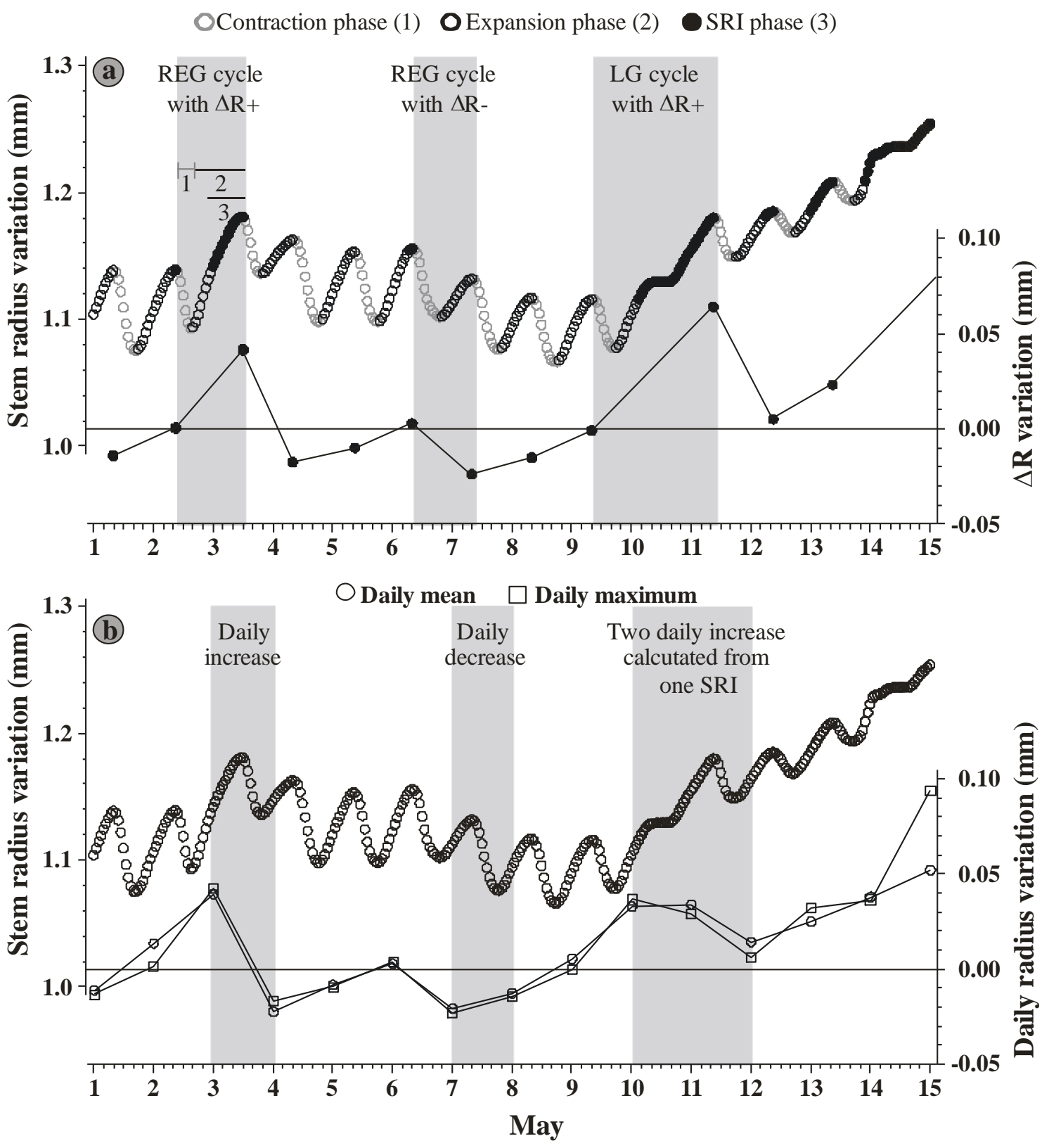
Figure 2

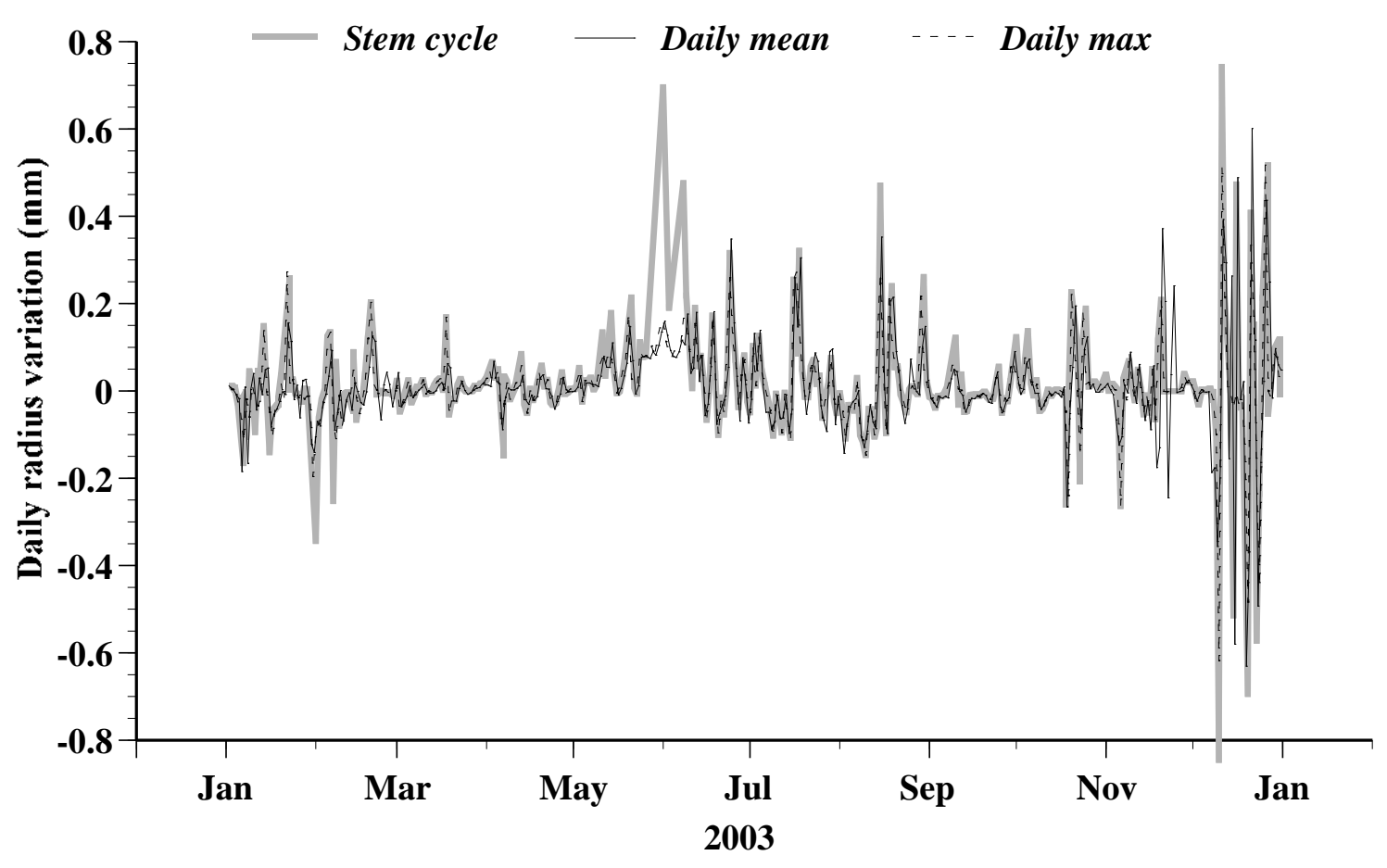


Figure 3

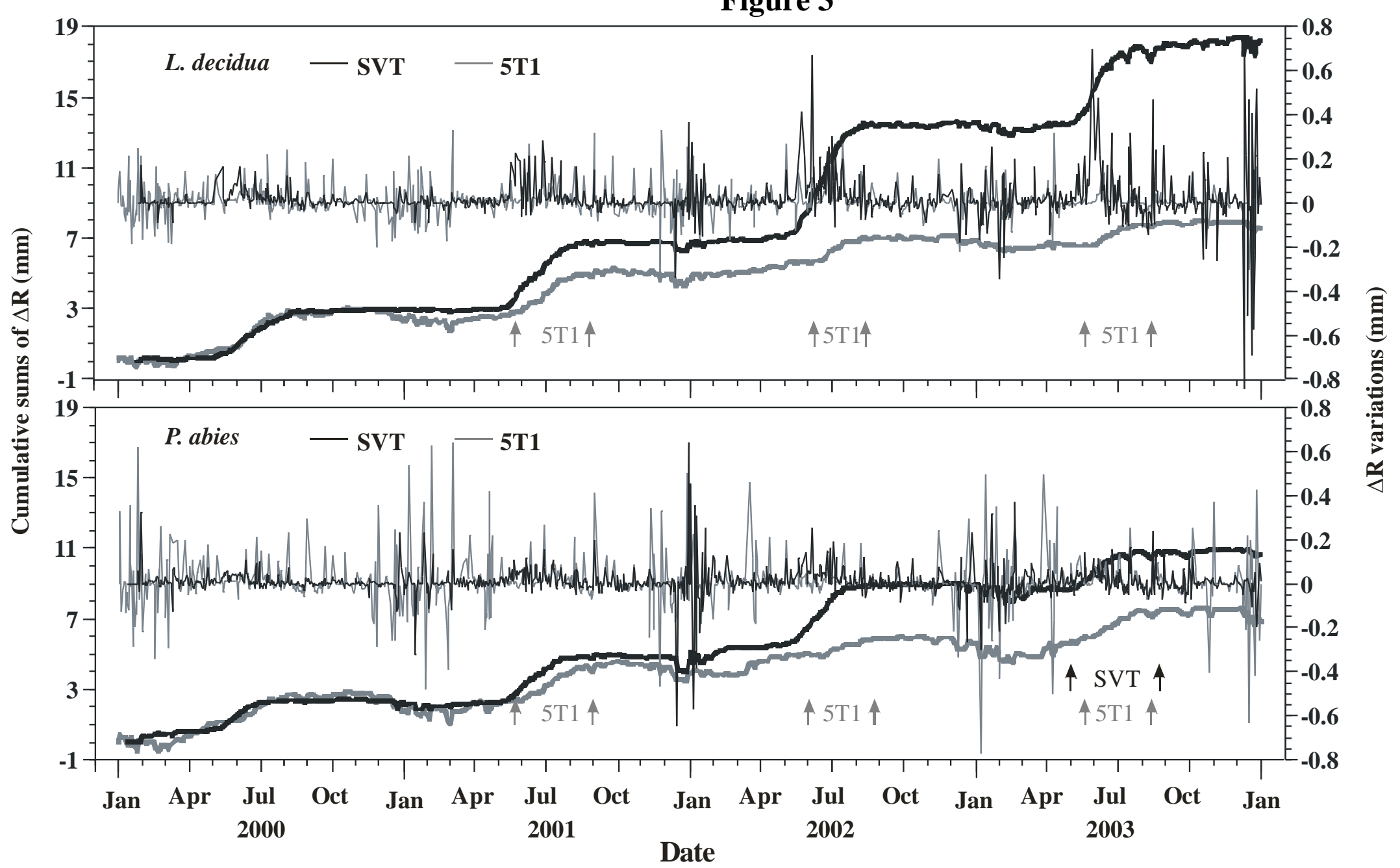


Figure 4

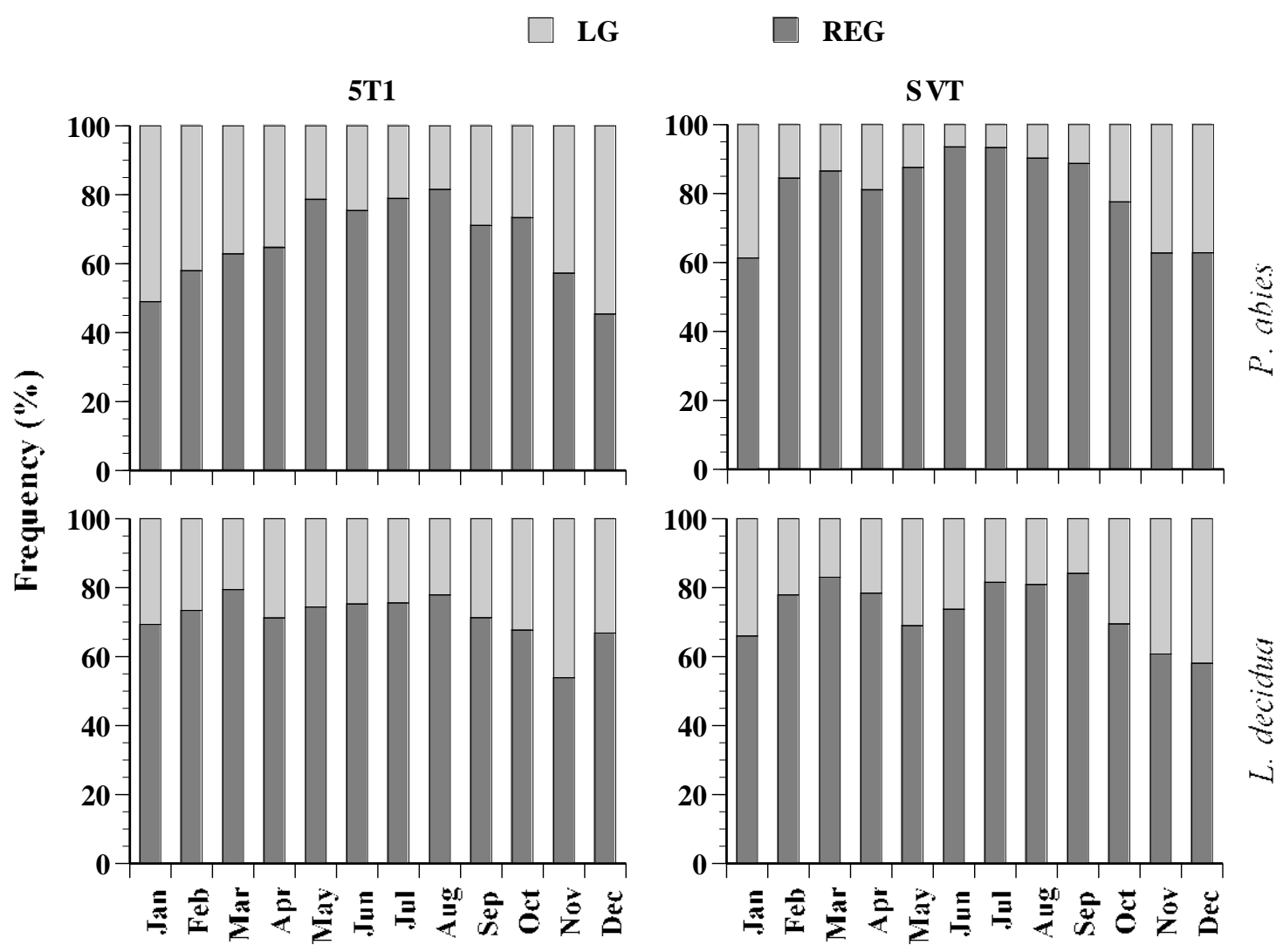


Figure 5

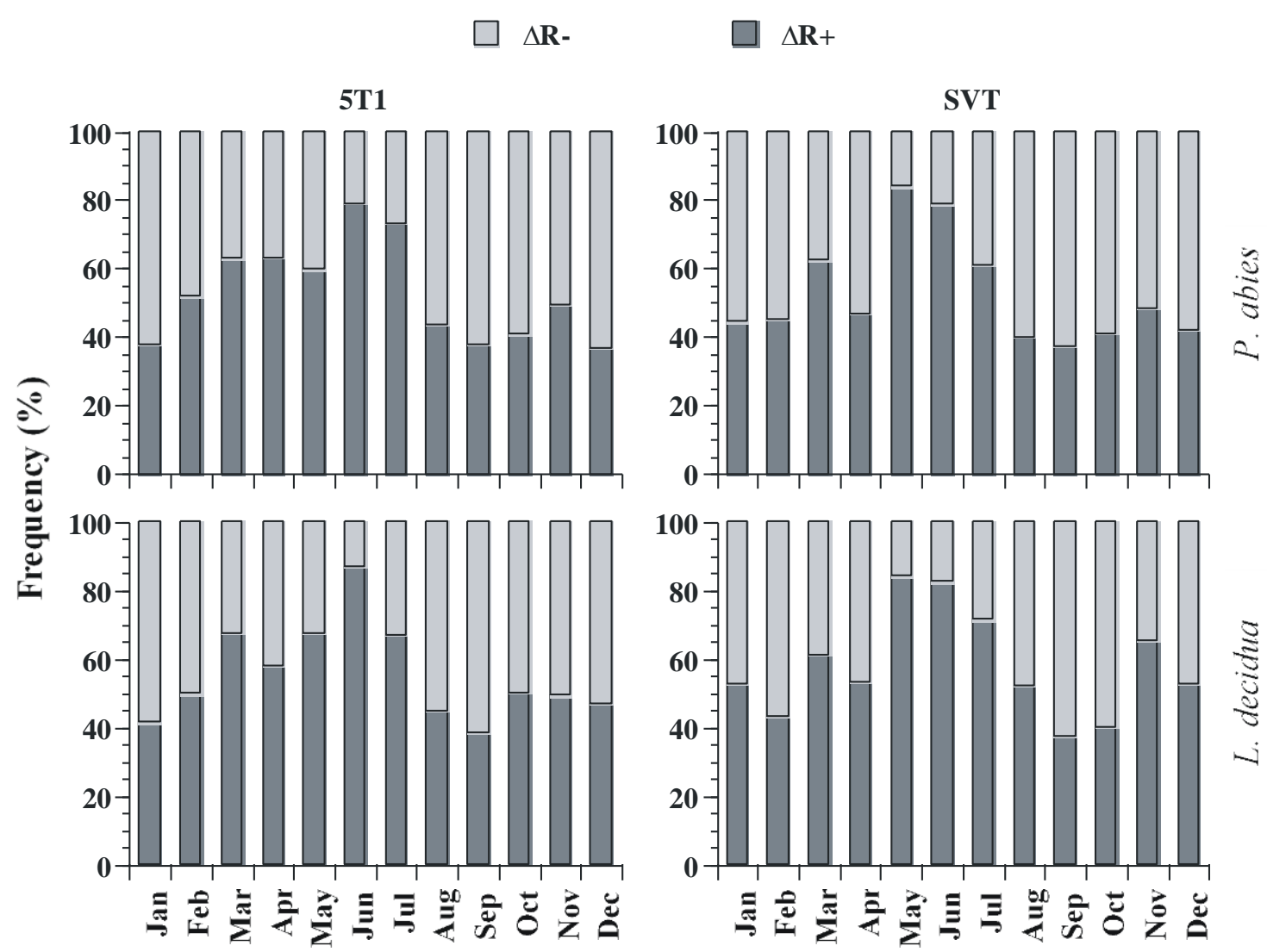


Figure 6
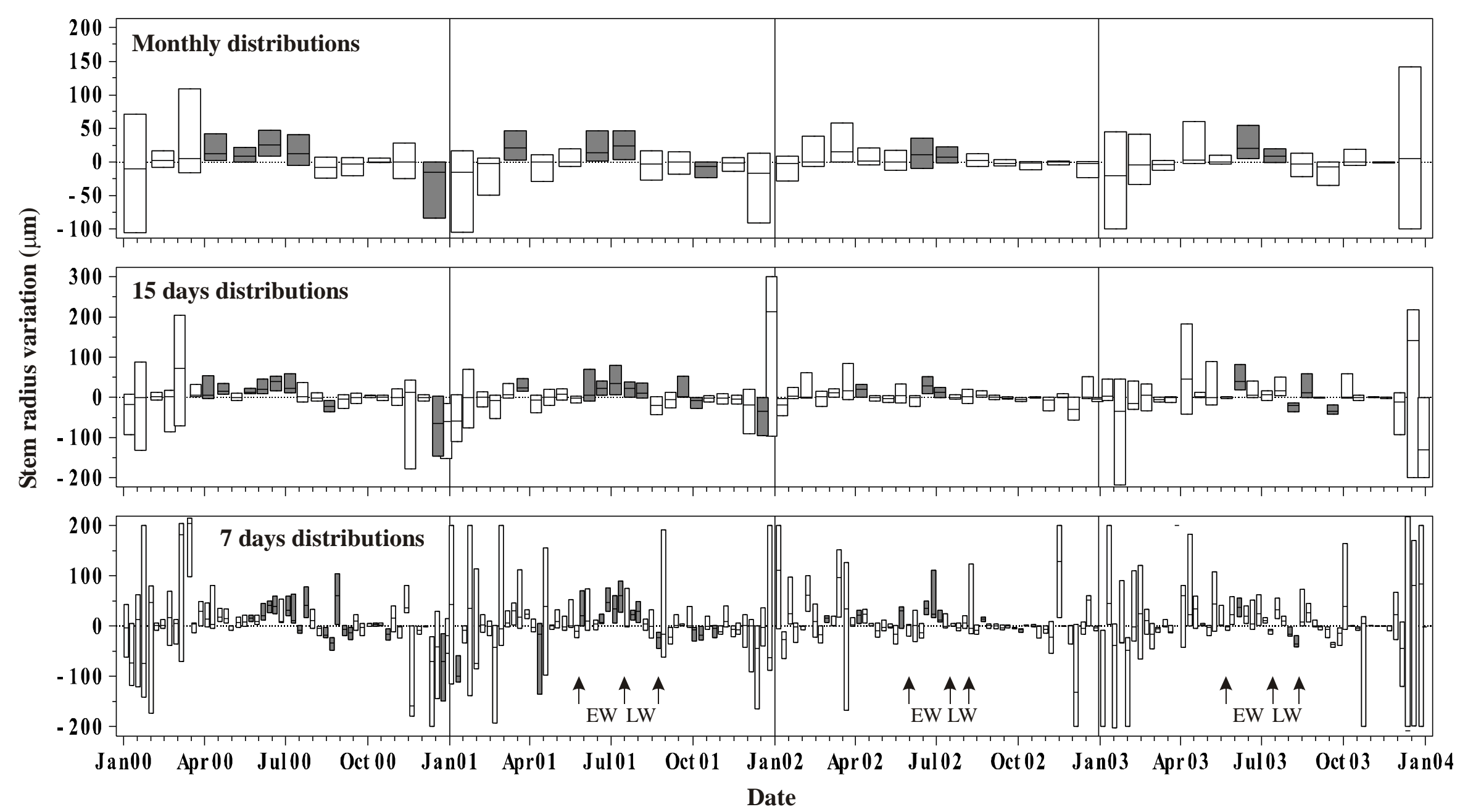


\section{Figure 7}
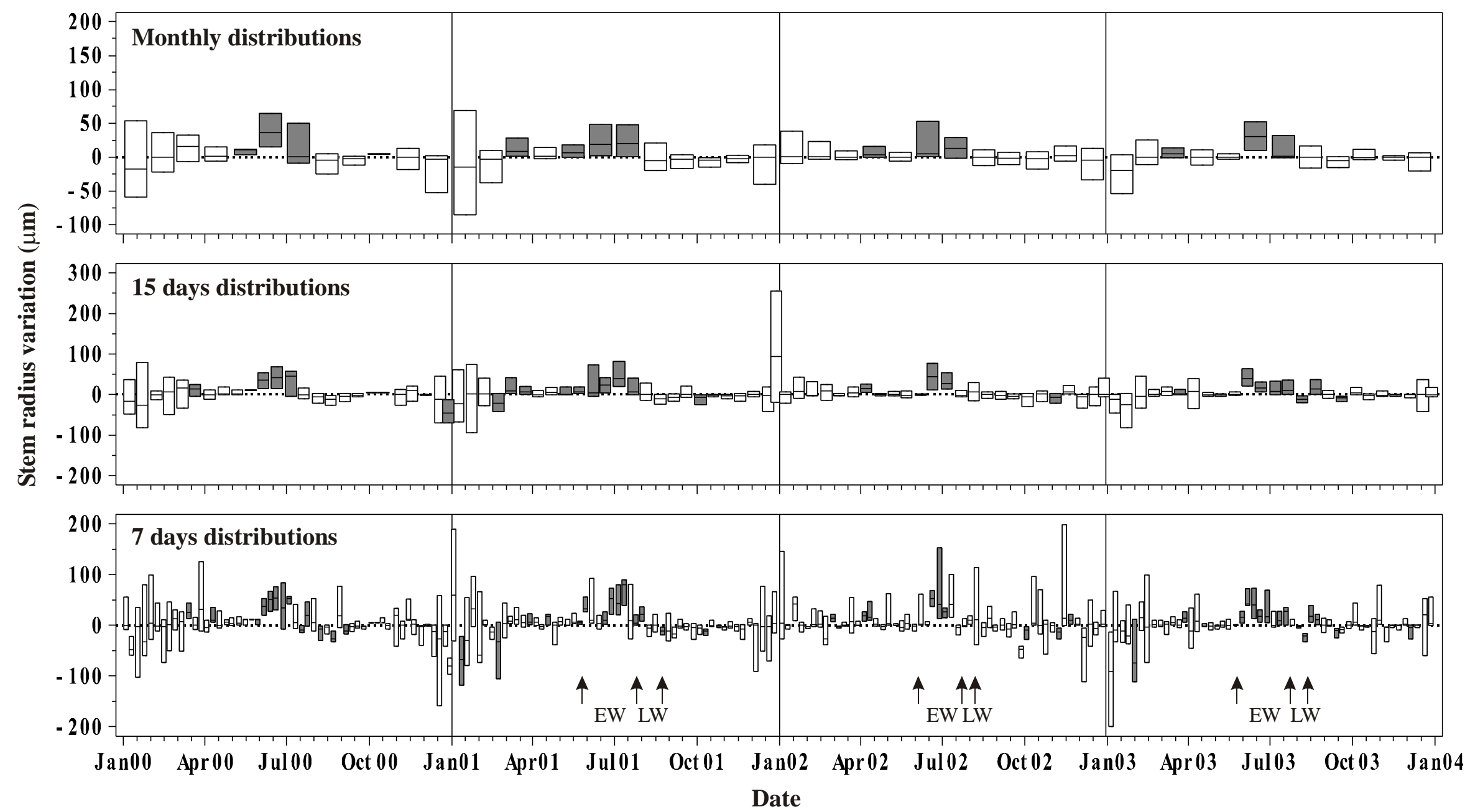
Figure 8
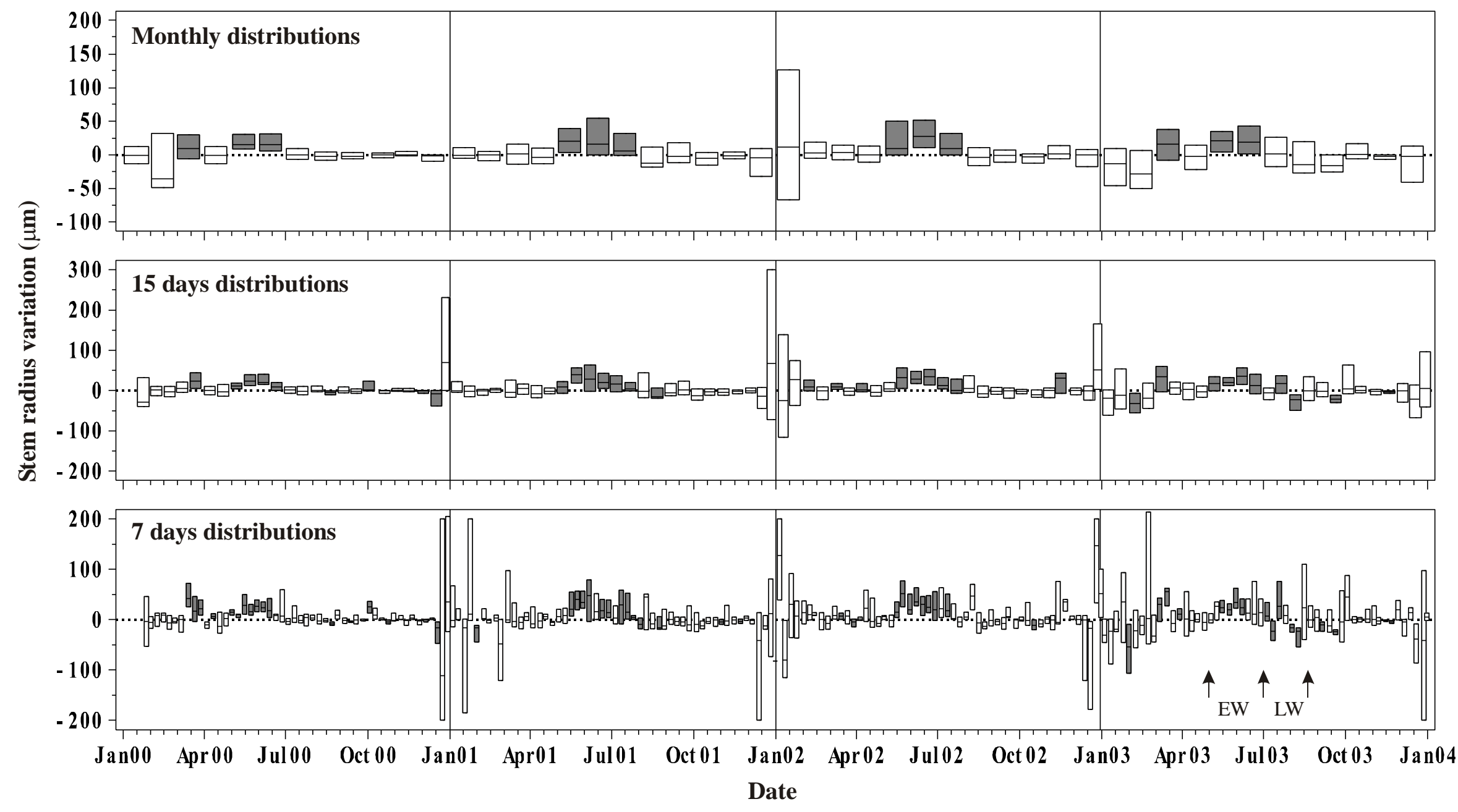


\section{Figure 9}

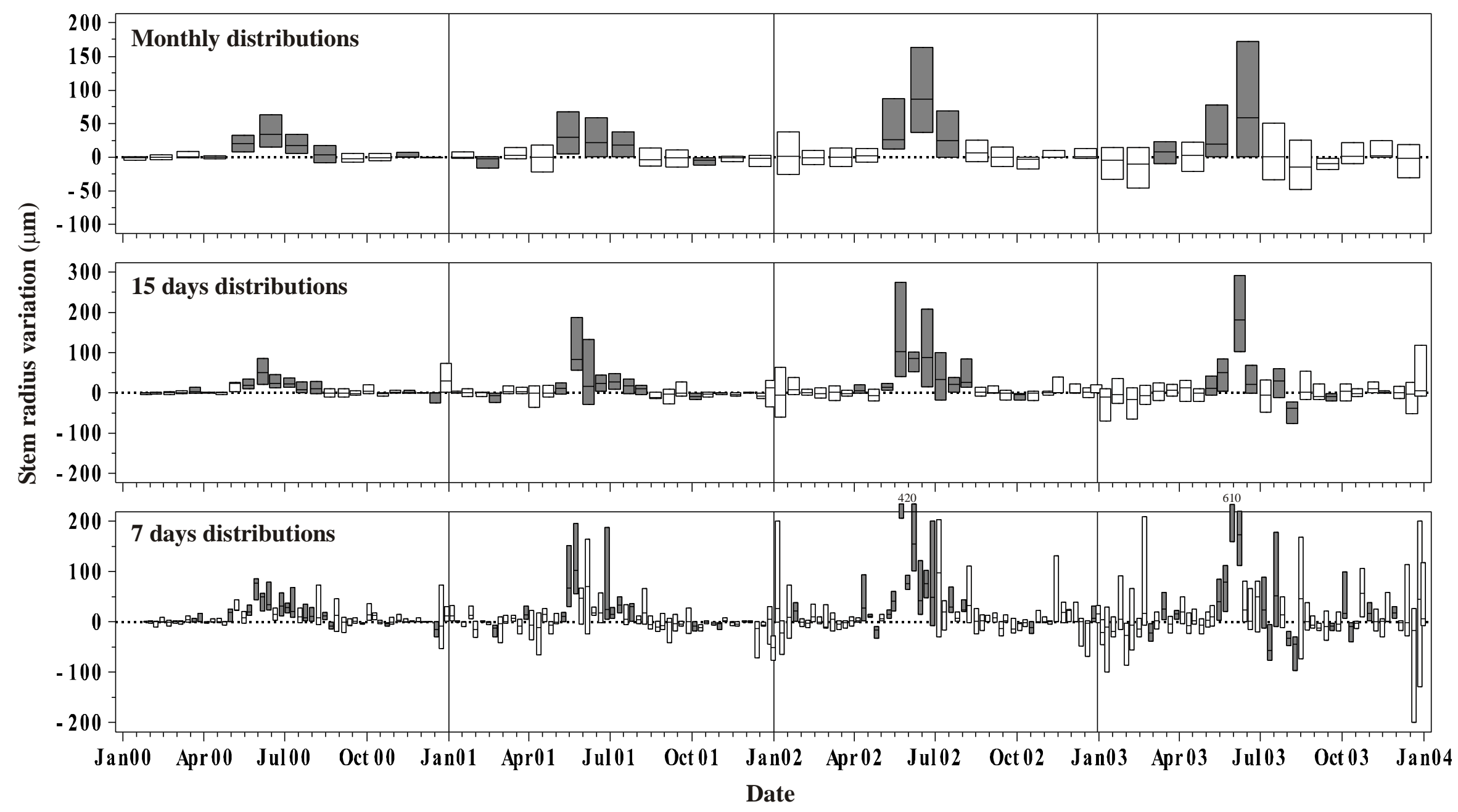

